I was fortunate enough to work with him for many years and owe him a debt that I am unable, fully, to express as a colleague, a friend and a family man. He had the support of his wife, two sons and daughter at all times. Only his daughter followed him into the medical profession, his sons taking after his other interest in the theatre. He himself was a fine actor, a producer and authority on English literature. His interest in natural history continued to his last days. He was a keen gardener and bred many somewhat esoteric animals in his collection of glasshouses.

A much loved man who will be sadly missed.

David M. Carter

\section{Professor Rashid Chaudhry}

Formerly Emeritus Professor and Chairman, Fountain House, Lahore, Pakistan

Professor Rashid Chaudhry died in Lahore on 13 August 2000. He was a pioneer in establishing psychiatry in Pakistan and started the first department of psychiatry in a general hospital in the country in the late 1960s and set the scene for expansion of this speciality in Pakistan. He was the first Professor of Psychiatry at King Edward Medical College, Lahore, and had served more than 15 years when he retired in 1982

He was born in East Punjab and his family migrated to Pakistan in 1947. After graduating from King Edward Medical College he joined the Army Medical Corps and served in northern areas for about 2 years. He then proceeded to the UK for further study at the Maudsley, after which he started his career as a specialist at the Mental Hospital, Lahore. He was elected FRCPsych in 1972

His vision to establish psychiatry as an important branch of medicine was reflected in his efforts to create more insight into mental health problems both among professionals and the general public. He also initiated the rehabilitation psychiatry in the country andfounded a rehabilitation facility in the name of 'Fountain House' at Lahore.
This facility is now regarded as an important innovation and is now widely accepted as a medium for treatment and training.

Professor Rashid Chaudhry was respected for his work and expertise all over the world. He was elected office bearer of different International organisations. He received various awards from the Government of Pakistan, United Nations Organization, World Health Organization, world psychiatric bodies and voluntary organisations. He was also very active in establishing the World Islamic Association for Mental Health and served this organisation as its president for more than 5 years.

He will be remembered by a large number of friends, associates and students. His dedication and contribution in the field of mental health will continue providing inspiration for his fellow colleagues in Pakistan. May God rest his soul in peace and give strength to his family and friends to bear his loss.

Afzal Javed

\title{
reviews
}

\section{Developing Primary Care for Patients with LongTerm Mental Illness. Your Guide to Improving Services}

By R. Byng, H. Single \& C. Bury. Kings Fund. 1999. 115 pp. f12.99 (pb). ISBN: 1-85717-271-X.

Books about general practice are interesting. Books about general practice written by non-general practitioners (GPs) telling us how to do it are often quite fun. Books about general practice written by GPs are useful; books written about general practice by a practising GP are rare and valuable. This book falls into the latter category. What makes it more interesting still is that it covers a topic that is poorly covered by either the research literature or by other authors the care of the severely mentally ill in primary care.

The book is clearly set out, describes the steps needed to undertake the various tasks, identifies why the tasks are important and what will be achieved by completing them. The descriptions throughout are simple, concise and designed with general practice in mind.

This is a book that is aimed (successfully) at primary care, but its attraction does not end there. It is of value to community mental health teams (CMHTs) in helping them understand some of the strengths and weaknesses of primary care, and what CMHTs can do to support primary care provide high quality care to a vulnerable population. It is of value to managers in primary care groups to help them provide direction to a mental health special interest group, always difficult if the managers themselves have no experience of commissioning or developing primary care mental health services. Overall it is a useful, well constructed book.

There is but one drawback - this review is published in a psychiatric journal, and not a primary care journal, which would raise the level of awareness significantly.

Alan Cohen FRCGP Head of Primary Care, Sainsbury Centre for Mental Health

\section{Primary Prevention of Mental, Neurological and Psychosocial Disorders}

World Health Organization. Geneva: WHO. 1998. 113 pp. SW.fr. 35-, Sw.fr. 24.50 in developing countries. ISBN: 92-4-154516-X.

This fairly short document forms the latest part of the World Health
Organization's (WHO) series of publications on mental disorder. It is aimed at professionals and policy makers in a variety of sectors who may be concerned with or who are in a position to influence the prevention of mental disorders. This is a welcome enterprise that can only serve to raise the profile of this neglected area.

The book provides a useful summary of our current medical knowledge of how to prevent four largely unrelated phenomena: mental retardation (i.e. learning disabilities), epilepsy, suicide and 'burnout'. However, it is seriously flawed in terms of the brief set by the WHO. It does not really attempt to address the wider interests of policy makers, neither does it present much of a coherent strategy for the prevention of mental disorders. Indeed, it is not clear that the four 'conditions' chosen make sense as the focus for a prevention strategy or that they sit naturally together either conceptually or practically. In many countries the agencies concerned with the prevention and 'treatment' (if relevant) of these conditions will be different.

The model adopted throughout is what is often, lazily, referred to as 'the medical model'. Information about the conditions is conceived of in purely medical terms and interventions are limited to the obvious traditional public health approaches. It is as if the authors have ignored the last 40 years of practice in 
terms of wider health promotion and community development, as well as broader perspectives on the conditions they address. It is telling that the concept of burnout is attributed to Freudenberger and addressed in a purely professional mental health context when the idea has been in common currency in the management literature and even general parlance for decades.

The fundamental problem is that the document starts by stating that the intention is to address a broad audience, but then jumps straight into a narrow and controversial definition of primary prevention. There is little acknowledgement of the ethical or social issues that surround the conditions discussed, or of the vastly different understandings of them that exist within and across different cultures. There is no recognition that much of the discussion is value laden and the terminology and assumptions may be inappropriate for the target audience. The concept of evidence as used in the publication is again very narrow and inappropriate to the subject and audience. To use randomised controlled trials as the gold standard for research in measuring effectiveness in burnout seems to be particularly inappropriate - although it may be much more suitable for the prevention of epilepsy.

The approach adopted means that certain interventions - iodization and reduction of alcohol intake in pregnancy in relation to mental retardation, for example - receive too much attention as opposed to wider interventions relating to public policy, eduction, community development and employment practices. In short, while this publication has some value in bringing together aspects of current knowledge, it fails in its objective of setting out some broad and deliverable prevention measures for mental disorders that could engage a wider audience of policy makers and practitioners. Such a text is still awaited.

Andrew McCulloch Head of Policy, The Sainsbury Centre for Mental Health, 134-138 Borough High Street, London SE1 1LB

\section{Locality Services in Mental Health. Developing Home Treatment and Assertive Outreach}

Edited by H. Wood \& S. Carr. London: The Sainsbury Centre for Mental Health. 1998. f15.00. ISBN: 1-870480-40-6.

This manual describes the reconfiguration of North Birmingham Mental Health Trust Locality Services. It gives an account of how services were "set up, run and sustained", with the intention of helping others "replicate the successes and avoid the pitfalls". It has an innovative layout, being presented as a pack of five removable booklets, each with a different emphasis.

The manual gives a good description of how the original locality services were evaluated, including desired areas for change. It gives a clear account of the proposed locality system. Community mental health teams are abandoned in favour of primary care mental health teams, with the addition of a home-based treatment team and assertive outreach team. The emphasis of the services described is on offering safe alternatives to hospital admission.

The booklets give clear accounts of how the teams were set up, from defining the services, operational policies and target populations, to recruitment, team skill mix and size, training and induction and daily functioning. There are also sections on 'a day in the life of', giving staff, user and carer perspectives. Advice on managing the process of change and the resistance to it is included, with offered project management strategies and worksheets to guide through the process of service development. Concise summaries of the evidence base for assertive outreach and home treatment and the model ingredients offer practitioners a ready reference. Funding for the development of the described homebased services was released by the delay of a replacement in-patient unit, with a resultant reduction in bed numbers. The authors acknowledge that additional funding provided by the Sainsbury Centre for Mental Health 'pump primed' the pilot scheme. Great effort was made to ensure the pilot project succeeded, owing to local scepticism that a reduction in bed usage could be achieved and sustained. A Sainsbury Centre for Mental Health evaluation of the home treatment team suggests that there was a $40 \%$ reduction in occupied bed days in 3 years. How much this was a result of the enthusiasm, hard work and gate-keeping to the in-patient unit of the home treatment team, rather than the intervention itself, is unclear.

In summary, this manual is comprehensive and well set out and has a lot to offer those developing local mental health services. It shows North Birmingham Mental Health Services in a glowing light. However, such optimism and enthusiasm may generate antibodies in some people whom, without such resources and clear guidance from the Sainsbury Centre, may find replication of these services unrealistic.

Dr Louise Guest Lecturer in Community Psychiatry, St George's Hospital School, Cranmer Terrace, London SW17 OR

\section{miscellany}

\section{Medical Managers in Psychiatry}

A medical managers in psychiatry group for the northern and Yorkshire region has been recently formed. The group includes medical and clinical directors in mental health services across the whole area and the group's intention is to provide opportunities for exchange of information and learning, to act as a reference group and also to act as a 'lobby' by engaging in discussion with key figures nationally and regionally. The group would be keen to hear from anyone who has set up a similar regional group. Those interested can contact Dr Hugh Griffiths, Medical Director, Northumberland Mental Health Trust at St George's Hospital, Morpeth, Northumberland, NE61 2NU; e-mail: hugh.griffiths@nmht.nhs.uk.

\section{NAPPS}

Narcolepsy Action for Positive \& Practical Solutions (NAPPS) is a new support group based in the UK. Initially set up by a narcolepsy sufferer from Yorkshire, NAPPS provides support, advice and information for those with narcolepsy and other groups and individuals wishing to learn more about the condition. NAPPS hopes to offer those with narcolepsy the opportunity to form contacts and links with other sufferers through the use of the internet. The organisation aims to raise awareness about the condition by producing publications and through local and national media, education and community involvement. This support group is keen to collaborate with other organisations and service providers both nationally and internationally. NAPPS can be contacted by e-mail: napps@cwcom.net or via their website http://www.napps.cwc.net. 